\title{
Browning of Pig White Preadipocytes by Co-Overexpressing Pig PGC-1 $\alpha$ and Mice UCP1
}

\author{
Lianjie Hou $\mathrm{Meiying} \mathrm{Xie}^{\mathrm{a}}$ Lingbo $\mathrm{Cao}^{\mathrm{a}}$ Jia Shi ${ }^{\mathrm{a}}$ Guli Xu${ }^{\mathrm{a}}$ Chingyuan $\mathrm{Hu}^{\mathrm{b}}$ \\ Chong Wang ${ }^{\text {a }}$
}

aNational Engineering Research Center for Breeding Swine Industry, Guangdong Provincial Key Lab of Agro-Animal Genomics and Molecular Breeding, College of Animal Science, South China Agricultural University, Guangzhou, Guangdong, PR China, 'bepartment of Human Nutrition, Food and Animal Sciences, College of Tropical Agriculture and Human Resources, University of Hawaii at Manoa, Honolulu, USA

\section{Key Words}

Ucp1 • Mitochondria $\cdot$ AMPK-SIRT1 pathway $\cdot$ PGC-1 $\cdot$ - Uncoupled respiration

\begin{abstract}
Background/Aims: Brown adipose tissue (BAT) is critical for mammals' survival in the cold environment. BAT-dependent non-shivering thermogenesis is attributed to uncoupling protein 1 (UCP1)'s disengagement of oxidative phosphorylation from ATP synthesis and dissipates energy as heat. Thus individuals with a substantial amount of BAT are better equipped during cold stress and less likely to become obese. Recently, our laboratory has shown pig adipocytes have no UCP1 protein. The inability of newborn piglets to generate heat contributed to its high death rate. Repairing the genetic defect of UCP1 in pig adipocytes has implications in defending against cold for piglets and developing an alternative treatment for human obesity. Methods: Q-PCR, western blotting (WB) and oxygen consumption measurement were used to enable functional UCP1 protein in preadipocytes. Immunoprecipitation (IP), chromatin immunoprecipitation (CHIP), and dual-luciferase reporter assay system were used to clarify the thermogenesis mechanism of functional UCP1. Results: Only co-overexpressing mice UCP1 and pig PGC-1 $\alpha$ increased not only the mitochondrial number but also the uncoupled respiration rate in the transfected pig adipocytes. The functional mice UCP1 increased the pig PGC- $1 \alpha$ activity through the AMPK-SIRT1 pathway. The active form PGC- $1 \alpha$ interacted with transcription factors $\mathrm{Lhx} 8, \mathrm{Zic} 1, \mathrm{ERR} \alpha$, and PPAR $\alpha$ to regulate the expression of mitochondrial energy metabolism and adipocytes browning-related genes. Conclusion: Our data suggest a model in which pig PGC-1 $\alpha$ and mice UCP1 work collaboratively to restore uncoupling respiration in pig preadipocytes. These results have great implications for piglet survival and developing an alternative treatment for human obesity in the future.




\section{Cellular Physiology Cell Physiol Biochem 2018;48:556-568 \\ and Biochemistry Published onIne: July 18, $2018 \quad \begin{aligned} & \text { DOI: 10.1159/000491885 } 2018 \text { The Author(s). Published by S. Karger AG, Basel } \\ & \text { www.karger.com/cpb }\end{aligned}$}

Hou et al.: UCP1/PGC-1 $\alpha$ Induce Pig Preadipocytes Browning

\section{Introduction}

Obesity has become a worldwide epidemic, and more research is focused on the physiology and biology of the adipose tissues. Most mammals have two different types of adipose tissues: white and brown [1]. The white adipose tissue (WAT) is mainly for energy storage while the brown adipose tissue (BAT) is for generating heat [2, 3]. In addition to the classic white and brown adipocytes, brown-like fat cells or beige adipocytes have been identified in recent years $[4,5]$. The non-shivering thermogenesis in the BAT disengages oxidative phosphorylation from ATP synthesis and dissipates energy as heat [6]. Individuals with a substantial amount of BAT are better equipped during cold stress and less likely to become obese [7-10]. Recent studies show humans have BAT, raising the question of whether activation of BAT and recruitment of the beige adipocytes can be a tool to combat the current obesity pandemic [11].

The uncoupling respiration mediated by UCP1 is the source of the non-shivering thermogenesis in brown and beige adipocytes [12-15]. UCP1 knockout mice were used to study the process of activation of brown adipocytes and recruitment of beige adipocytes [1618]. UCP1 null mice are cold sensitive, and UCP1 is responsible for the brown adipose tissue non-shivering thermogenesis function [19]. However, over one-half of adult humans have no functional UCP $[1,20]$; therefore, there is still much work to do to establish the molecular mechanism of UCP1 thermogenesis.

Our laboratory has shown the UCP1 gene is naturally truncated and is not translated in the pig adipose tissues [21]. Our findings indicate pigs have no brown adipose tissue, which explains the weak thermogenic ability of the piglets [21]. A recent study has shown UCP1 transgenic pigs could improve the piglet's weak thermogenic ability [20]. However, their in vitro study did not detect the uncoupling respiration in the adipocytes isolated from the transgenic pigs [20]. Additional research will be needed to establish the mechanisms associated with the browning of the pig adipocytes. Since pigs have no brown adipose tissue and lots of white adipose tissue, it is an excellent model for studying the browning of white adipose tissue.

The peroxisome proliferator-activated receptor coactivator-1 $\alpha(P G C-1 \alpha)$ is a transcriptional co-activator that interacts with many transcription factors (NRFs, ERRs, and PPARs) to regulate mitochondrial biogenesis and adaptive thermogenesis [22-25]. Overexpressing $P G C-1 \alpha$ in human white adipocytes has been shown to induce human white adipocytes to acquire the brown adipocyte features [26]. However, there is no report on the roles of $P G C-1 \alpha$ in pig mitochondrial biogenesis and adaptive thermogenesis.

The objectives of this study are to repair the UCP1 gene defect in pig adipocytes enabling the adipocytes to obtain the uncoupling respiration in vitro and to explore the underlying mechanisms involved. Our results demonstrated co-overexpressing mice UCP1 and pig PGC$1 \alpha$ enabled pig preadipocytes to acquire uncoupling respiration ability. We also found the functional mice UCP1 increased pig PGC- $1 \alpha$ activity in pig preadipocytes. In turn, PGC- $1 \alpha$ interacts with transcription factors Lhx8, Zic1, ERR $\alpha$, and PPAR $\alpha$ to regulate mitochondrial biogenesis and adaptive thermogenesis in pig preadipocytes. These results have implications for neonatal pigs to defend themselves against the cold and for developing an alternative treatment for human obesity.

\section{Materials and Methods}

All animals used in this study were reared and euthanized with the approval of the College of Animal Science, South China Agricultural University. All experiments were performed following the guidelines and regulations of 'the instructive notions with respect to caring for laboratory animals' issued by the Ministry of Science and Technology of the People's Republic of China.

RNA extraction and PCR analysis

Methods used for the RNA extraction and PCR analysis have been described previously [21]. The relative expression of mRNAs and microRNA were normalized with $\beta$-actin levels using the ${ }^{\Delta} \mathrm{Ct}$ method 
[27]. ${ }^{\Delta \Delta} \mathrm{Ct}$ is defined as the ratio of the relative mRNA level of the target gene between the experimental group and the control group. Primers were designed using Primer Premier 5 according to the pig genes sequence obtained from NCBI. The sequences of the primers used in this study are listed in Table 1.

\section{Cell experiment}

The pig preadipocytes in primary culture were isolated from the subcutaneous back fat pad of 1-day old male Landrace pigs according to previously published protocols [21] with following modifications. Briefly, subcutaneous adipose tissue was dissected and finely minced after removing all visible connective tissues. Then the minced tissue was digested for $40 \mathrm{~min}$ at $37^{\circ} \mathrm{C}$ in isolation buffer $(125 \mathrm{mM} \mathrm{NaCl}, 5 \mathrm{mM}$ $\mathrm{KCl}, 1.3 \mathrm{mM} \mathrm{CaCl}{ }_{2}, 5 \mathrm{mM}$ glucose, $100 \mathrm{mM}$ HEPES, $4 \%$ BSA, $1.5 \mathrm{mg} / \mathrm{mL}$ Collagenase B). Digested tissue was filtered through a $70 \mu \mathrm{m}$ cell strainer to remove large pieces, and the flow-through was centrifuged for 10 min at $500 \times \mathrm{g}$ to collect stromal-vascular fraction (SVF) cells in the pellet. The SVF cells were suspended in the growth medium, which is DMEM/F12 (GIBCO, Grand Island, NY, USA) containing 15\% fetal bovine serum (FBS, GIBCO), 100, 000 units/L of penicillin sodium, and $100 \mathrm{mg} / \mathrm{L}$ of streptomycin sulfate (GIBCO). The SVF cells were then plated in $75 \mathrm{~cm}^{2}$ cell culture flasks. For plasmid transfection, primary adipocytes with $60 \%$ confluency were incubated with plasmids for six hours in the growth medium. Then the medium was replaced with new growth medium and cells were maintained in growth medium for an additional 24 h. All other chemicals were purchased from Sigma-Aldrich (St. Louis, Missouri, USA).

\section{Mitochondrial DNA content quantification by $q-P C R$}

Genomic DNA was isolated from different cells. The cells were digested with Proteinase K overnight in a lysing buffer for DNA extraction by the conventional phenol-chloroform method. The results were calculated from the difference in the threshold cycle values for mitochondrial DNA and nuclear-specific

Table 1. PCR primers used in this study

\begin{tabular}{|c|c|c|}
\hline Gene name & Forward primer sequence ( $\left.5^{\prime}-3^{\prime}\right)$ & Reversed primer sequence (5'-3') \\
\hline$\beta$-actin & GCGGGACATCAAGGAGAAGC & TGTCGGCGATGCCTGGGTA \\
\hline Pig UCP1 & GGTCACCGCCAAAGTCCG & CAGCCCTCTGTAGTGCTTCATT \\
\hline Mice UCP1 & AGAGGTCGTGAAGGTCAGAATG & GGCTTGGTACGCTTGGGT \\
\hline PGC- $1 \alpha$ & TGACAGCGAAGATGAAAGTGA & GATTTGGGTGGTGATACGG \\
\hline AP2 & AAAACTACGGAGATTGCCTTCA & GCTACATTCСАCСАССААСТTАТ \\
\hline Leptin & CAAGCAGTGCCTATCCAGAAAG & GGTGAAGCCCAGGAATGAAGT \\
\hline AdipoQ & ACCTTTGTGGGAACCTGGAA & CCTGTCGTCTGCGGTGATT \\
\hline CD24 & GGTAGACCACTCGCATTCCTTT & CCCACAGACTCGGCACTCA \\
\hline HMGA2 & CGCACACCGCCAAAGTC & ATGCCAGTCACCAGAAGGAA \\
\hline Lhx8 & GAGGCACATCCATTCTACCG & AGGAGGGCACCTTCAACAC \\
\hline Zic1 & TCTACСТTCСТTCTGGTGACTG & TGCCGTGACTCCATCAACTCT \\
\hline Cidea & ATGACAGTTCCTGAAGTGCCC & GCGGTGTCCAAAGTGCAA \\
\hline Hspb7 & GGGCCTGGCAACATCAA & CTTCTCAGCTCGCACCTCAAT \\
\hline Dio2 & CGGGACATCAAGGAGAAGC & GCACTGTGTTGGCGTAGAG \\
\hline PDK4 & AGATTTCAGACAGAGGAGGTGGT & TATGCTGGCAAAGAGTAGAGGTT \\
\hline CD40 & CCTGCCCAGTTGGCTTCT & CTGCTCCTTGGTCACCTTTCT \\
\hline CD137 & CCAGGACTGTATGTGGAGCG & AGCCAAGGGTTCGGGACT \\
\hline TBX1 & АTCTTCTCATTGTTATTGGGTCT & TTGTGTTCGTGGAGGCTTTT \\
\hline Tmem26 & TGGTCCCTTCCTGGTTGTG & GCCTGCTGGCTTACTTCTCA \\
\hline SLC27A1 & GGATGGGAAGGTTGGTGC & AGAGGGTCCTGCTGGTTGAT \\
\hline TFAM & GACCTCTGTGCGGTTTGTG & ACCTGCCAGTCTGCCCTAT \\
\hline FABP1 & AAGGGGAAGGACATCAAGG & CAGTCAGGGTCTCCATCTCAC \\
\hline MCAD & GTGCСССTTATTATTGGTGG & TTCTGCTTTGGTCTTTATCCC \\
\hline CPT-1 $\beta$ & GCACGGCAACTGCTACAACA & CAGGGCGATCTGCACGAA \\
\hline ACOX I & GCAACCGAGGAGTTCATTCT & СTTCACCTGGGCATACTTCAT \\
\hline ATP synthase & СТСТААТАACCGCACAATCTCG & TGTAATGTTGGCTGTCAGTCGT \\
\hline Cyt C & CGACTCGTCCAAACCTCCA & СТТСССТТТСТСССТТСТТСТТА \\
\hline Lhx8 & ATGGCCTCGGGCTCCGTCTGC & TTAGGTATGACTTATTGGCAGT \\
\hline Zic1 & ATGCTCCTGGACGCCGGCCC & TTAAACGTACCATTCGTTAAA \\
\hline AMPK & GTATGCTGGTCCAGAGG & AAAGGCTAATCACAGAAGG \\
\hline SIRT1 & AGTACAGACTTCTAGGAGCAT & TACCATCAAGCCGTTTA \\
\hline COX III & ATGGCATCTGGAGGTGGTG & GCTGGGTCTCGCCTTTGT \\
\hline
\end{tabular}




\section{Cellular Physiology Cell Physiol Biochem 2018;48:556-568 \begin{tabular}{ll|l} 
and Biochemistry Published onlıne: July 18, 2018 & $\begin{array}{l}\text { C) } 2018 \text { The Author(s). Published by S. Karger AG, Basel } \\
\text { www.karger.com/cpb }\end{array}$ \\
\hline
\end{tabular} \\ Hou et al.: UCP1/PGC- $1 \alpha$ Induce Pig Preadipocytes Browning}

gene by q-PCR. The data are expressed as mitochondrial DNA-specific 16S ribosomal RNA normalized to nuclear-specific gene hexokinase, which was described by Lagouge et al $[28,29]$..

Western blot analysis

The method used for the Western blot analysis has been described previously [21]. The sources and names of antibodies used in this study are listed in Table 2 . The protein quantification was performed using Image J (Bethesda, USA).
Table 2. The details of antibodies used in this study

\begin{tabular}{lcccc}
\hline Primary antibody & Clone & \multirow{2}{*}{ Company } & Catalog No. & \multirow{2}{*}{ Dilution } \\
\hline PGC-1 $\alpha$ & Monoclonal & Abcam & ab54481 & $1: 2000$ \\
TBX1 & Polyclonal & Abcam & ab109313 & $1: 2000$ \\
Zic1 & Monoclonal & Abcam & ab134951 & $1: 2000$ \\
Lhx8 & Monoclonal & Abcam & ab137036 & $1: 2000$ \\
UCP1 & Polyclonal & Bioss & bs-1925R & $1: 700$ \\
FABP1 & Polyclonal & Bioss & bs-0824R & $1: 500$ \\
MCAD & Polyclonal & Bioss & bs-4047R & $1: 500$ \\
ATP synthase & Polyclonal & Bioss & bs-8600R & $1: 500$ \\
$\beta$-Actin & Monoclonal & Bioss & bsm-33036M & $1: 1000$ \\
Secondary antibody & Conjugate Used & Company & Catalog No. & Dilution \\
& & & & \\
Goat Anti-rabbit IgG & HRP & Bioss & bs-0295G & $1: 3000$ \\
\hline
\end{tabular}

Determination of Cellular Respiration

We used Oxygen Consumption/Mito Membrane Potential Dual Assay Kit (Cayman, Michigan, USA) to measure the oxygen consumption rate of the pig adipocytes. This kit utilizes the phosphorescent oxygen probe MitoXpress-Xtra to measure oxygen consumption rate in living cells. The MitoXpress-Xtra probe lifetime signal has a negative correlation with oxygen concentration. In short, pig preadipocytes transfected with different recombinant vectors were collected $24 \mathrm{~h}$ later by $0.05 \%$ trypsin digestion. Cells $(30,000$ cells per well) were seeded in 96-well cell culture plate, and $120 \mu \mathrm{L}$ culture medium, $10 \mu \mathrm{L}$ MitoXpress-Xtra Solution and $10 \mu \mathrm{L}$ different treatments (oligomycin, FCCP or Antimycin A) were added to each well. Then, $100 \mu \mathrm{L}$ HS Mineral Oil was gently added to each well. Each plate was read once every five min for $90 \mathrm{~min}$. Uncoupled and maximal oxygen consumption rates were determined using oligomycin (14 mM) and FCCP (10 mM). Antimycin A (4 mM) was used to inhibit Complex III-dependent respiration.

The ATP concentration of the pig adipocytes was determined using an ATP Assay Kit according to the manufacturer's instructions (Beyotime, Shanghai, China).

\section{Transmission Electron Microscopy}

The mitochondrial number in pig adipocytes was examined by transmission electron microscopy (TEM). Pig adipocytes were collected $36 \mathrm{~h}$ after transfecting with different vectors using $0.05 \%$ trypsin. Cells were fixed in $2.5 \%(\mathrm{w} / \mathrm{v})$ glutaraldehyde in PBS (pH 7.4) at $4{ }^{\circ} \mathrm{C}$ for $24 \mathrm{~h}$ and then fixed in $2 \%(\mathrm{w} / \mathrm{v}$ ) osmium tetraoxide at $4{ }^{\circ} \mathrm{C}$ for $1 \mathrm{~h}$. Dehydration was done in an ascending concentration series of ethanol at $25^{\circ} \mathrm{C}$. Samples were embedded in Quetol 812 and sectioned to $90 \mathrm{~nm}$ by Leica EM UC6 Ultramicrotome (Leica Company). Then the section was viewed with a Tecnai 12 transmission electron microscope (FEI Company).

\section{Statistical analysis}

All data are expressed as the mean \pm standard error of the mean (S.E.M.), and at least three independent individuals or replicates were used per group. The assumptions of normality of data and homogeneity of variances between the groups were analyzed by SPSS. Significant differences between treatment groups were determined by one-way ANOVA (SPSS 18.0, Chicago, IL, USA). Significance was achieved when $p<0.05$. $*$ is $p<0.05$ and ${ }^{* *}$ is $p<0.01$.

\section{Results}

Overexpression of truncated pig UCP1 protein failed to induce uncoupled respiration in pig preadipocytes

We have shown pig has truncated UCP1 gene with only three exons, and two of them are transcribed, but not translated in the adipose tissues. We wanted to know what happens if we overexpress the cloned truncated pig UCP1 gene (two exons) in pig preadipocytes. So we expressed the truncated pig UCP1 protein in pig preadipocytes using the pcDNA3.1 (+)-pig UCP1 recombinant vector. Through q-PCR (Fig. 1A) and WB (Fig. 1B), we found the 
recombinant vector expressed pig UCP1 mRNA and pig UCP1 protein highly in the pig preadipocytes. Then we examined whether the truncated pig UCP1 protein has the thermogenic ability by measuring the uncoupled respiration rate in the preadipocytes. The truncated pig UCP1 did not increase pig preadipocytes oxygen consumption in the presence of oligomycin (an ATP synthase inhibitor) (Fig. 1C). These results indicate the truncated pig UCP1 protein is not functional.

\section{Overexpression of mice UCP1 protein failed to induce uncoupled respiration in pig preadipocytes}

Since pig UCP1 is a truncated and non-functional gene, we want to know whether by introducing the mice $U C P 1$ gene we can restore the uncoupled respiration in pig preadipocytes. We transfected pig preadipocytes with pcDNA3.1 $(+)$ - mice UCP1 recombinant vector or pcDNA3.1 (+). Using q-PCR (Fig. 2A) and WB (Fig. $2 B$ ), we found the recombinant vector expressed highly the mice UCP1 mRNA and mice UCP1 protein in pig preadipocytes. However, mice UCP1 did not increase pig preadipocytes oxygen consumption in the presence of oligomycin (Fig. 2C) when we measured the uncoupled respiration rate in these preadipocytes. These results indicate overexpression of mice UCP1 protein does not affect uncoupled respiration of pig preadipocytes.

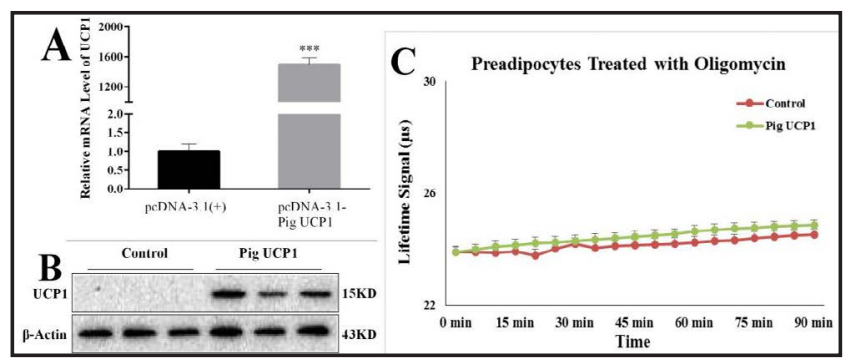

Fig. 1. Overexpression of truncated pig UCP1 protein failed to induce uncoupled respiration in pig preadipocytes. (A) UCP1 mRNA level was increased in pig preadipocytes after transfected with pcDNA3.1 (+)-pig UCP1 recombinant vector. (B) UCP1 protein was expressed in pig preadipocytes after transfected with pcDNA3.1 (+)-pig UCP1 recombinant vector. (C) Overexpression of the truncated pig UCP1 gene did not affect uncoupled respiration of pig preadipocytes. We used Oxygen Consumption/Mito Membrane Potential Dual Assay Kit to measure continuous oxygen consumption in transfected pig preadipocytes. The MitoXpress-Xtra probe phosphorescent lifetime signal increased as the oxygen concentration decrease. The results are presented as Mean \pm S.E.M. of three replicates for each group. ${ }^{* * *} \mathrm{P}<0.001$.

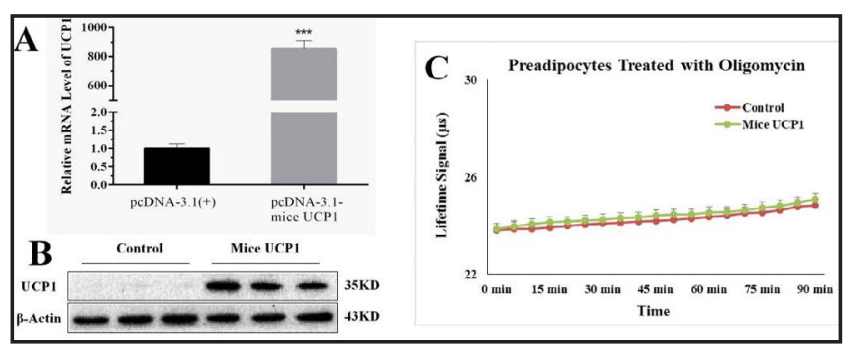

Fig. 2. Overexpression of mice UCP1 protein failed to induce uncoupled respiration in pig preadipocytes. (A) Mice UCP1 mRNA level was increased in pig preadipocytes after transfected with pcDNA3.1 (+)-mice UCP1 recombinant vector. (B) Mice UCP1 protein was expressed in pig preadipocytes after transfected with pcDNA3.1 (+)-mice UCP1 recombinant vector. (C) Overexpressing the mice UCP1 gene did not affect uncoupled respiration of pig preadipocytes. We used Oxygen Consumption/Mito Membrane Potential Dual Assay Kit to measure continuous oxygen consumption in transfected pig preadipocytes. The results are presented as Mean \pm S.E.M. of three replicates for each group. $* * * \mathrm{P}<0.001$.

Overexpression of pig PGC-1 $\alpha$ and mice UCP1 enabled pig preadipocytes to acquire uncoupled respiration

$P G C-1 \alpha$ is recognized as a master regulator of mitochondrial biogenesis and has a close positive relationship with adaptive thermogenesis. Since overexpression of mice UCP1 alone did not restore the uncoupled respiration in the pig preadipocytes, we explored whether co-overexpressing $P G C-1 \alpha$ and $U C P 1$ allows pigs to acquire uncoupled respiration. Results from the q-PCR and WB indicate the construction of overexpression models were successful (Fig. 3A, 3B). Moreover, the Western blot (WB) result shows co-overexpressing pig $P G C-1 \alpha$ 
and mice UCP1 increased mice UCP1 protein compared with overexpressing mice UCP1 alone. However, co-overexpressing $P G C-1 \alpha$ and pig UCP1 did not increase pig UCP1 protein compared with overexpressing pig UCP1 alone. By measuring the uncoupled respiration rate in preadipocytes, we found only cooverexpressing pig $P G C-1 \alpha$ and mice $U C P 1$ in pig preadipocytes increased oxygen consumption in the presence of oligomycin (Fig. 3C). These results indicate co-overexpressing pig $P G C$ $1 \alpha$ and mice UCP1 induced pig preadipocytes to acquire the ability for uncoupled respiration.

Overexpression of $P G C-1 \alpha$
increased the mitochondrial
biogenesis in pig
preadipocytes
Since $P G C-1 \alpha$ is a master regulator of mitochondrial biogenesis, we examined the number and morphology of mitochondria in these pig preadipocytes by transmission electron microscopy. We found there are more mitochondria (indicated by the red arrowheads) in $P G C$ - $1 \alpha$ overexpression groups (Fig. 4A, 4B). Consistent with the TEM observation results, we found $P G C-1 \alpha$ overexpression increased pig preadipocytes mitochondrial DNA copy number (Fig. 4C).

Co-overexpression of pig PGC-1 $\alpha$ and mice UCP1 increased the expression of genes associated with mitochondrial energy metabolism and oxygen consumption in pig preadipocytes

Since mitochondrial $\mathrm{H}^{+}$is the substrate for UCP1 to exert its uncoupling respiration function, we measured the expressions of mitochondrial oxidative phosphorylation-related genes and fatty acid oxidation-related genes, and the maximal oxygen consumption of the preadipocytes. Fig. 5A shows overexpressing pig $P G C-1 \alpha$ increased $(\mathrm{P}<0.05)$ mRNA levels of the mitochondrial oxidative phosphorylation-related genes such as ATP synthase, Cytochrome C (Cyt C), and Cytochrome C oxidase subunit III (COX3); and mRNA levels of the fatty acid oxidation-related genes, such as fatty acid binding protein 1 (FABP1), carnitine palmitoyltransferase $1 \mathrm{~B}(C P T-1 \beta)$, acyl-CoA oxidase 1 (ACOX1), and medium chain acylCoenzyme A dehydrogenase $(M C A D)$ in pig preadipocytes. Fig. 5B shows overexpressing pig PGC-1 $\alpha$ increased the protein levels of the ATP synthase, COX3, FABP1, and MCAD in pig preadipocytes. However, compared with overexpressing $P G C-1 \alpha$, co-overexpressing pig $P G C-1 \alpha$ and mice UCP1 increased CPT-1 $\beta$ and ATP synthase mRNA levels in pig preadipocytes (Fig. 5A). As a robust uncoupled agent, FCCP transports $\mathrm{H}^{+}$through the mitochondrial inner membrane to provide energy for the oxidative phosphorylation. In the presence of FCCP, cells showed the maximal oxygen consumption. This oxygen consumption reflects mitochondrial $\mathrm{H}^{+}$production rate. As shown in Fig. 5C, after co-overexpressing pig PGC-1 $\alpha$ and mice UCP1, pig preadipocytes acquired the highest oxygen consumption among all the groups in the presence of FCCP. These results indicate pig preadipocytes co-transfected with pig PGC$1 \alpha$ and mice UCP1 have elevated mitochondrial energy metabolism. Most likely, increased 
Fig. 4. Overexpression of PGC$1 \alpha$ increased the mitochondrial biogenesis in pig preadipocytes. (A) The morphology and number of mitochondria were observed by transmission electron microscopy. The arrows show some representative mitochondria. Fig. a-f represent pig preadipocytes transfected with pcDNA3.1 (+), pcDNA3.1 (+)-pig UCP1, pcDNA3.1 $(+)$-mice UCP1, pcDNA3.1 (+)-PGC$1 \alpha, \quad$ pcDNA3.1 (+)-PGC-1 $\alpha+$ pcDNA3.1 (+)-pig UCP1, pcDNA3.1 $(+)-P G C-1 \alpha+$ pcDNA3.1 (+)mice UCP1, respectively. (B) The quantitative data of mitochondrial number in Fig. A. (C) Mitochondrial DNA copy number was increased in pig preadipocytes after overexpressing PGC- $1 \alpha$. The results are presented as Mean \pm S.E.M. of three replicates for each group. ${ }^{* *}$ $\mathrm{P}<0.001$.

Fig. 5. Co-overexpression of mice UCP1 and pig PGC- $1 \alpha$ increased the expression of genes associated with mitochondrial energy metabolism and oxygen consumption in the pig preadipocytes. (A) Cooverexpressing mice UCP1 and pig PGC-1 $\alpha$ elevated mRNA levels of the mitochondrial oxidative phosphorylation-related and fatty acid oxidation-related genes in pig preadipocytes. (B) Cooverexpressing mice UCP1 and pig PGC- $1 \alpha$ elevated protein levels of mitochondrial biogenesis, fatty acid oxidation, and oxidative phosphorylation-related genes

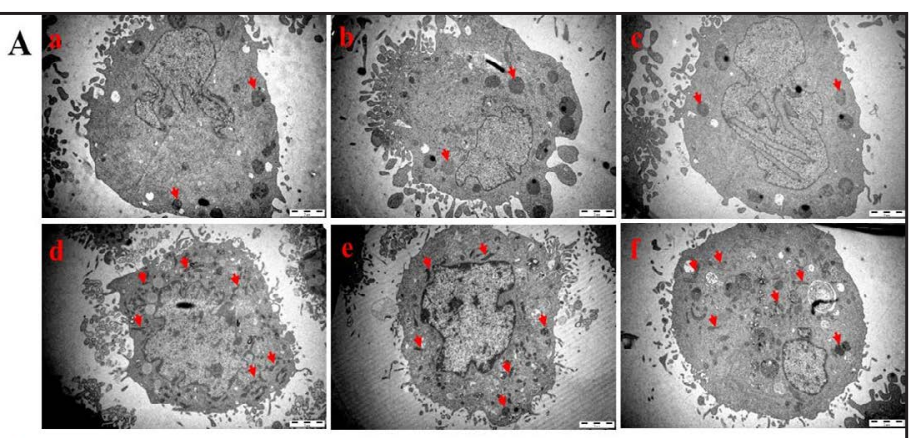

B

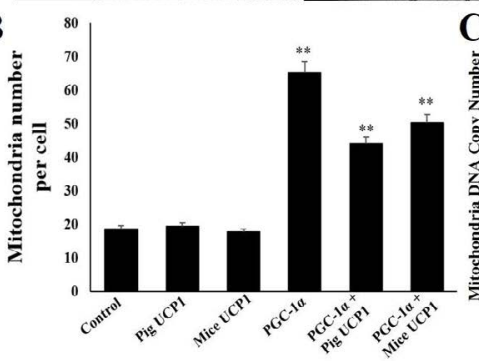

C

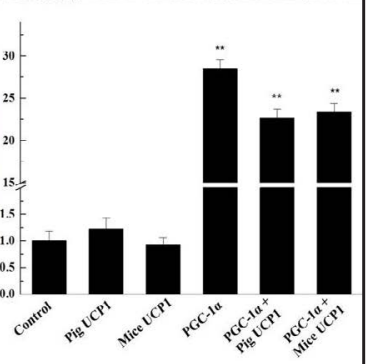

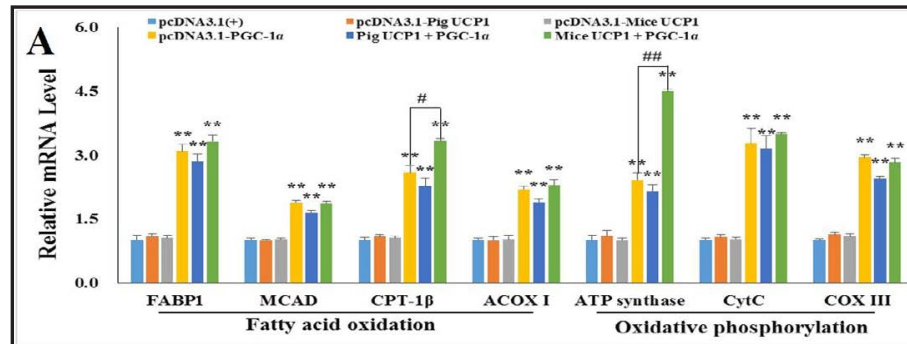
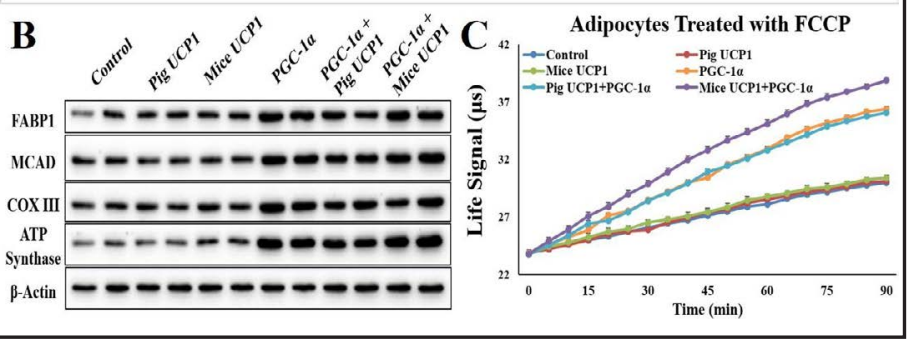

p-Actin

L

in pig preadipocytes. (C) Co-overexpressing mice UCP1 and pig PGC-1 $\alpha$ increased mitochondrial oxygen consumption in the pig preadipocytes. We used Oxygen Consumption/Mito Membrane Potential Dual Assay Kit to measure continuous oxygen consumption in transfected pig preadipocytes. The results are presented as Mean \pm S.E.M. of three replicates for each group. * indicates a difference between treatments (transfected with different recombinant vectors) and control (pcDNA3.1), and \# indicates a difference between pcDNA3.1-PGC-1 $\alpha$ transfection group and PGC-1 $\alpha+$ Mice UCP1 co-transfection group. $\mathrm{N}=3$, **, $\mathrm{P}<0.01 ; \#, \mathrm{P}<0.05 ; \# \#, \mathrm{P}<0.01$.

mitochondrial $\mathrm{H}^{+}$production provided sufficient substrate allowing the UCP1 to exert its uncoupling respiration.

\section{KARGER}


Co-overexpression of pig PGC-1 $\alpha$ and mice UCP1 increased the expression of brown/beige adipocyte marker genes in pig preadipocytes

Since co-overexpressing pig $P G C-1 \alpha$ and mice $U C P 1$ induced pig preadipocytes to acquire the ability for uncoupled respiration, we also measured the expression of brown and beige adipocyte marker genes in preadipocytes transfected with pig PGC-1 $\alpha$ and mice UCP1. Compared with control, co-overexpressing pig $P G C-1 \alpha$ and mice $U C P 1$ in pig preadipocytes increased mRNA levels of brown and beige adipose tissue markers Lhx8, Zic1, Cidea, PDK4, CD137, and SLC27a1 (Fig. 6). However, compared with overexpressing pig $P G C-1 \alpha$ alone, co-overexpressing pig $P G C$ - $1 \alpha$ and mice $U C P 1$ in preadipocytes decreased $(\mathrm{P}<0.05)$ Lhx 8 mRNA level; and increased $(\mathrm{P}<0.05)$ mRNA levels of Cidea, CD137, and SLC27a1 (Fig. 6). These results indicate co-overexpressing pig $P G C-1 \alpha$ and mice UCP1 induced browning of pig preadipocytes.

Functional UCP1 increased PGC-1 $\alpha$ activity through activating the AMPK-SIRT1 signal pathway

Since the function of UCP1 is to disperse the energy used to generate ATP in the form of heat, we measured the ATP level in the pig preadipocytes transfected with pig $P G C-1 \alpha$ and mice UCP1. As shown in Fig. 7A, compared with overexpressing pig $P G C-1 \alpha$ alone, cooverexpressing pig $P G C-1 \alpha$ and mice $U C P 1$ decreased the cellular ATP level. The reduction of cellular ATP led to elevated mRNA levels of AMPK and SIRT1 (Fig. 7B). Reduction of cellular ATP level also increased the protein levels of pAMPK, the active form of AMPK, and SIRT1. The active form of PGC- $1 \alpha$ is either de-acetylated or phosphorylated, and SIRT1 activation reduced PGC-1 $\alpha$ acetylation (Fig. 7C). To further investigate the phosphorylation of PGC-1 in this process, we mutated the acetylation site of the PGC-1 gene (PGC- $\alpha-\mathrm{M})$ and transfected it into pig preadipocytes. By measuring the uncoupled respiration rate in these transfected pig preadipocytes, we found there was still uncoupled respiration in the pig preadipocytes after transfected with pig $P G C-\alpha-M$ and mice $U C P 1$. These results indicate functional UCP1 increased PGC- $1 \alpha$ activity through activating the AMPK-SIRT1 signal pathway.

$P G C-1 \alpha$ regulated the expression of mitochondrial energy metabolism and adipocytes browning-related genes

To further explore the mechanism of co-overexpressing pig PGC-1 $\alpha$ and mice UCP1 induced preadipocytes browning mediated by the active PGC- $1 \alpha$, we investigated the

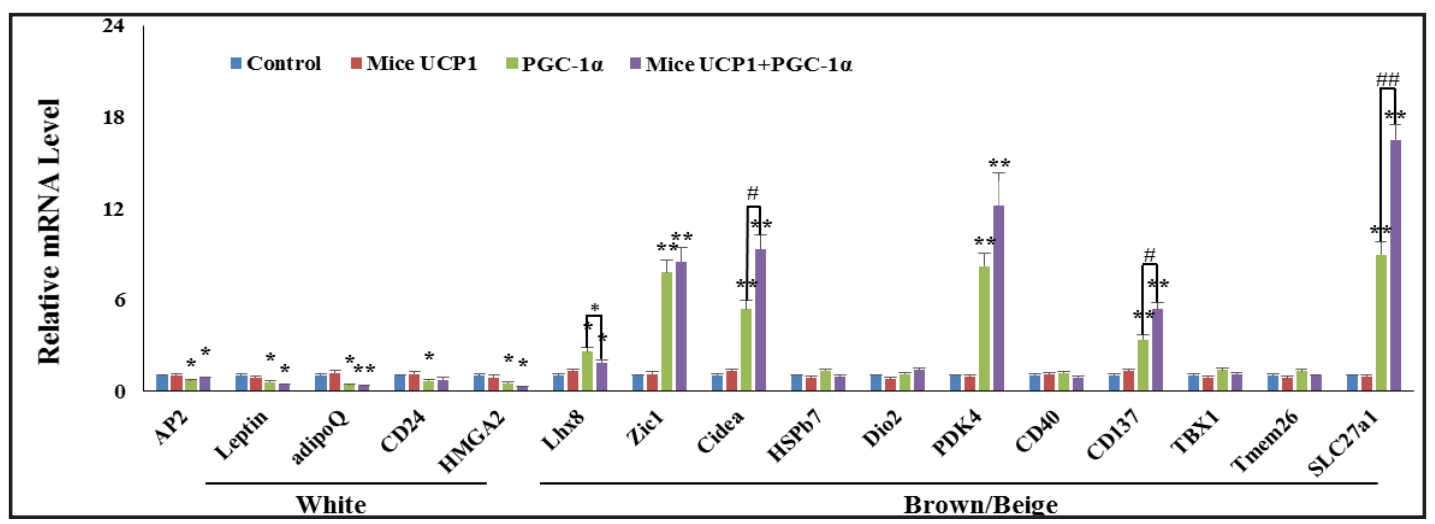

Fig. 6. Co-overexpression of pig PGC- $1 \alpha$ and mice UCP1 increased the expression of brown/beige adipocyte marker genes in pig preadipocytes. The expressions of brown and beige adipocyte marker genes were measured in preadipocytes transfected with pig PGC- $1 \alpha$ and mice UCP1. The results are presented as Mean \pm S.E.M. of three replicates for each group. * indicates a difference between treatments (transfected with different recombinant vectors) and control (pcDNA3.1), and \# indicates differences between PGC-1 $\alpha$ transfection group and PGC- $1 \alpha+$ Mice UCP1 co-transfection group. $\mathrm{N}=3$, ${ }^{* *}, \mathrm{P}<0.05, * *, \mathrm{P}<0.01 ; \#, \mathrm{P}<0.05$; \#\#, $\mathrm{P}<0.01$.

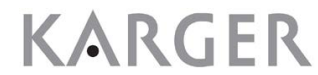


interactions of browning-related transcription factors with PGC- $1 \alpha$ through IP. As shown in Fig. 8A, after pig preadipocytes transfected with pig $P G C-1 \alpha$ and mice $U C P 1$ interacted with transcription factors Lhx8, Zic1, ERR $\alpha$, and PPAR $\alpha$. Through CHIP, we found a binding site in the promoter region of CPT-1 $\beta$ for Lhx8, a binding site in the promoter region of TFAM for Zic1, a binding site in the promoter region of $P D K 4$ for ERR $\alpha$, and a binding site in the promoter region of SLC27a1 for PPAR $\alpha$ (Fig. 8B). Finally, we confirmed the regulatory relationship between the genes and transcription factors through the dual luciferase reporter system. As shown in Fig. 8C, after the recombinant vector transfected in HEK-293 cell, Lhx8 decreased the relative luciferase activity of pGL3-basic-CPT-1 $\beta$ promoter recombinant vector, and even more pronounced reduction in the presence of PGC- $1 \alpha$ (Fig. 8C). Zic1 increased the relative luciferase activity of pGL3-basic-TFAM promoter recombinant vector, and the trend was further increased in the presence of PGC- $1 \alpha$ (Fig. 8C). Similar results were also observed for the ERR $\alpha$ with PDK5 and PPAR $\alpha$ with SLC27a1 (Fig. 8C). These results indicate $\mathrm{PGC}-1 \alpha$, as a transcriptional co-activator, regulated mitochondrial energy metabolism and the expression of adipocytes browning-related genes. Thus, our data suggest a model in which pig PGC- $1 \alpha$ and mice UCP1 work collaboratively to restore uncoupling

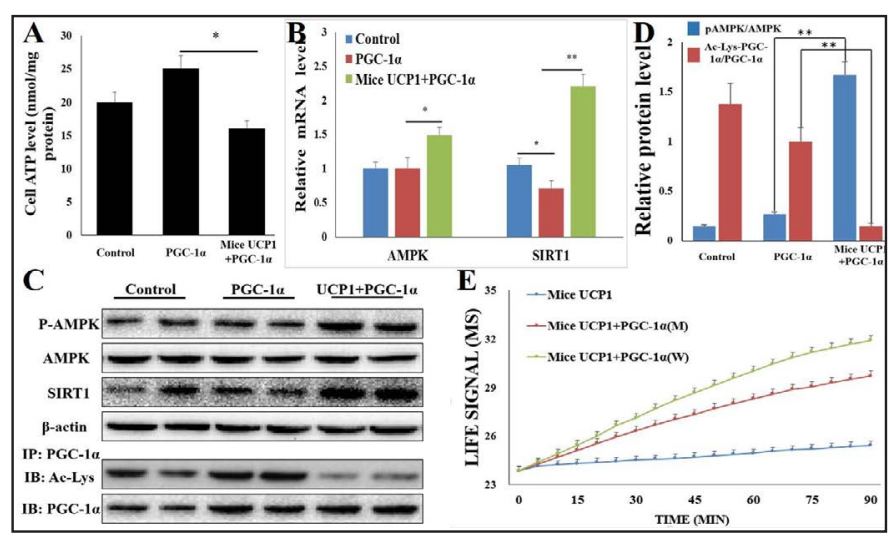

Fig. 7. Functional UCP1 increased PGC-1 $\alpha$ activity through activating the AMPK-SIRT1 signal pathway. (A) Functional UCP1 decreased the ATP level in preadipocytes. (B) Functional UCP1 increased AMPK and SIRT1 mRNA levels in pig preadipocytes. (C) Functional UCP1 increased pAMPK and SIRT1 protein levels and decreased the acetylation level of PGC- $1 \alpha$ in pig preadipocytes. (D) The gray-scale scan of the WB results. (E) Pig preadipocytes acquired uncoupling respiration after co-transfected with pig PGC$\alpha-\mathrm{M}$ and mice UCP1. The results are presented as Mean \pm S.E.M. of three replicates for each group. ${ }^{*} \mathrm{P}<0.05,{ }^{* *} \mathrm{P}<0.01$.

Fig. 8. PGC- $1 \alpha$ regulated the expression of mitochondrial energy metabolism and adipocytes browning related genes. (A) IP assays showed transcriptional co-activator PGC-1 $\alpha$ interacted with transcription factors Lhx8, Zic1, ERR $\alpha$, and PPAR $\alpha$. (B) ChIP assays showed Lhx8 binds directly to the CPT- $1 \beta$ promoter region, Zic1 binds directly to the TFAM promoter region, ERR $\alpha$ binds directly to the PDK4 promoter region, and PPAR $\alpha$ binds directly to the SLC27a1 promoter region. (C) DualLuciferase Report Gene System results confirmed the regulatory relationship between the transcription factors and the genes. The results are presented as Mean \pm S.E.M. of three replicates for each group. ${ }^{*} \mathrm{P}<0.05,{ }^{* *} \mathrm{P}<0.01$, ${ }^{* * *}$ $\mathrm{P}<0.001$.

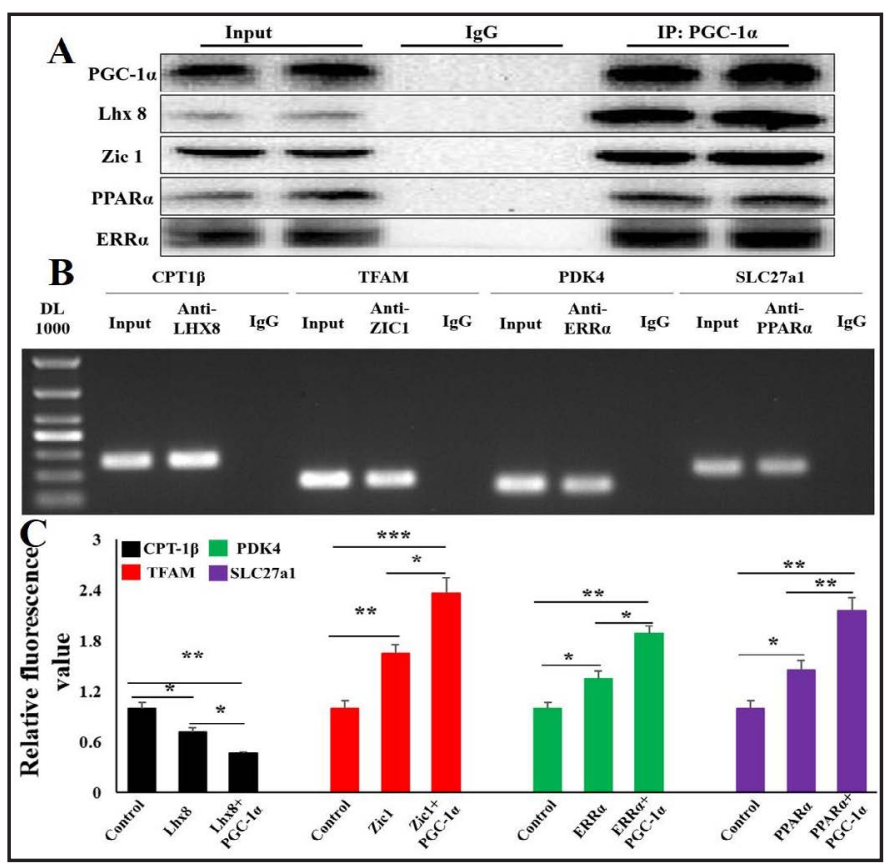


respiration in pig preadipocytes (Fig. 9).

\section{Discussion}

BAT is essential for most mammals to maintain body temperature homeostasis in cold environment. BAT-dependent non-shivering thermogenesis requires the UCP1 [30]. Increasing non-shivering thermogenesis through activating BAT or obtaining BAT-like characteristics in WAT might be an alternative strategy for piglets surviving the cold environment or treating obesity in humans $[31,32]$. Since the UCP1 defect leads to poor thermogenic ability in piglets, we attempted to restore the ability of uncoupling respiration in the pig preadipocytes and analyze the mechanism of the pig $P G C-1 \alpha$ and mice UCP1 work collaboratively to restore uncoupling respiration in pig preadipocytes.

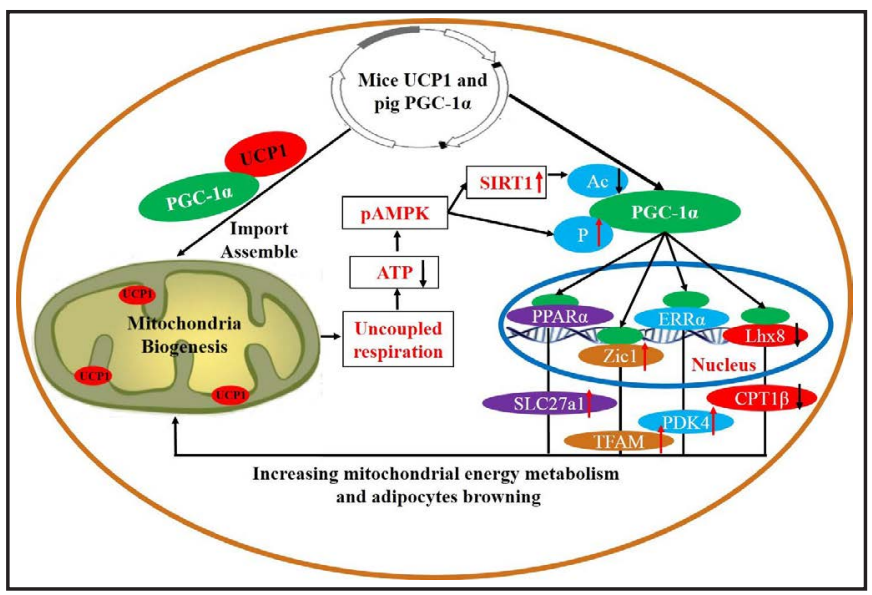

Fig. 9. Model of how pig PGC- $1 \alpha$ and mice UCP1 interact at the genetic and functional levels to restore uncoupling respiration in pig preadipocytes. Overexpression of pig PGC- $1 \alpha$ promotes mitochondrial biogenesis in pig preadipocytes. In this process, mice UCP1 assembled into the mitochondrial inner membrane to exert its function. The uncoupled respiration of functional UCP1 increased pAMPK and SIRT1 protein levels. The de-acetylation of SIRT1 and the phosphorylation of pAMPK increased the PGC-1 $\alpha$ activity. The active transcriptional co-activator PGC- $1 \alpha$ interacted with transcription factors Lhx8, Zic1, ERR $\alpha$, and PPAR $\alpha$ regulated mitochondrial energy metabolism and the expression of preadipocytes browning-related genes. Thus, co-overexpressing mice UCP1 and pig PGC- $1 \alpha$ restored uncoupling respiration in pig preadipocytes.

To perform the uncoupling respiration function, UCP1 needs to be transported and assembled to the mitochondrial inner membrane, and the $\mathrm{H}^{+}$must be available as the substrate [33]. Consistent with this, brown or beige adipocytes contain a large number of mitochondria and UCP1 that correspond to the high level of PGC- $1 \alpha$, whereas PGC- $1 \alpha$ expression is much lower in white adipocytes [34]. PGC-1 $\alpha$ has been shown to have a close relationship with adaptive thermogenesis and is a master regulator of mitochondrial biogenesis [35]. These mechanisms may be the causes for overexpressing either pig or mice UCP1 alone, failed to induce uncoupled respiration of pig preadipocytes. Therefore, we introduced pig $P G C-1 \alpha$ and $U C P 1$ to repair the $U C P 1$ defect. Our results demonstrate co-overexpressing pig $P G C-1 \alpha$ and mice $U C P 1$ enabled pig preadipocytes to acquire the ability for uncoupled respiration. These results indicate overexpressing pig $P G C-1 \alpha$ promoted mitochondrial biogenesis in pig preadipocytes, and assembled mice UCP1 into the mitochondrial inner membrane to exert its function. In addition, our result shows the PGC- $1 \alpha$ was barely detectable in pig adipose tissue (Fig. 3B). The lower expressed PGC- $1 \alpha$ level may explain why UCP1 knock-in pigs did not obtain the uncoupling respiration ability in the adipose tissue [20]. We did not observe any noticeable color change in pig preadipocytes transfected with pig $P G C-1 \alpha$ and mice $U C P 1$. The single-layer cells grown in the cell culture plates may have contributed to this lack of color change. However, we did observe increased mitochondria number.

TBX1 is a specific beige adipocyte marker for mice, but not for humans because there is no difference in TBX1 expression between human brown and beige adipocytes [36]. While Eva1 is thought to be a specific marker for mice brown adipocytes, but not for human infants, because Eva1 is highly expressed in the perirenal adipose tissue (a WAT site), not the interscapular adipose tissue (a BAT site) [20]. These studies indicate that the brown and beige adipocyte markers are only species-specific. At the same time, we found that 
most brown and beige adipocyte markers are related to the cellular energy metabolism. Since the objective of this study was to establish whether we could restore the uncoupled respiration in the pig preadipocytes, we do not distinguish the markers between brown or beige adipocytes.

In our study, compared with overexpressing pig $P G C$ - $1 \alpha$ alone, co-overexpressing pig $P G C-1 \alpha$ and mice $U C P 1$ in pig preadipocytes elevated the mRNA levels of $C P T-1 \beta$, ATP synthase, Cidea, CD137, and SLC27a1; and lowered the Lhx8 mRNA level. These changes may result from the functional UCP1 increased the activity of the PGC- $1 \alpha$. Since UCP1 disengages ATP synthesis from the oxidative phosphorylation and dissipates energy as heat, this process leads to faster substrate oxidation and a lower rate of ATP production. AMPK is the cellular energy sensor; low ATP level activates AMPK [37]. Then the AMPK activates PGC-1 $\alpha$ via phosphorylation and de-acetylation through the AMPK-SIRT1 pathway. In our study, we confirmed the functional mice UCP1 increased pig PGC-1 $\alpha$ activity through activating the AMPK-SIRT1 signal pathway in the pig preadipocytes.

PGC- $1 \alpha$ as a transcriptional co-activator interacts with other transcription factors, which regulate the expressions of fatty acid oxidation, oxidative phosphorylation, and mitochondrial biogenesis related genes [38-40]. Through the use of IP assay, we found ERR $\alpha, \operatorname{PPAR} \alpha, \operatorname{Lhx} 8$, and Zic1 interact with PGC- $1 \alpha$ in pig preadipocytes transfected with pig PGC-1 $\alpha$ and mice UCP1. Of all these four transcription factors, only ERR and PPAR have been reported to exist in the mice and human brown adipocytes [41]. Lhx8 and Zic1 are used only as the brown/ beige adipocyte marker genes in the previous studies $[42,43]$. We are not aware of any report on the function of Lhx8 and Zic1 in adipocytes. The function of Lhx8 is mostly related to the WNT signaling pathway and regulation of Maxillary Arch Cells proliferation [44]. Most studies about Zic1 are focused on the differentiation of neurons [45, 46]. However, Zic1 is known to regulate the expression of BMPs for neural fate determination [47]. Meanwhile, BMP4 increases the browning of white adipose tissue [48], and BMP8b increases the nonshivering thermogenesis in the brown adipose tissue [49]. Future studies should include whether Zic1 regulates brown adipose tissue non-shivering thermogenesis through BMPs.

In conclusion, our results show co-overexpressing pig $P G C-1 \alpha$ and mice UCP1 induced pig preadipocytes to acquire the ability for uncoupled respiration. The functional UCP1 increased the PGC- $1 \alpha$ activity through the AMPK-SIRT1 pathway. Finally, the active transcription co-activator PGC-1 $\alpha$ interacted with transcription factors Lhx8, Zic1, ERR $\alpha$, and PPAR $\alpha$ to regulate mitochondrial energy metabolism and the expression of preadipocytes browning-related genes. Additional work in vivo is needed to ascertain whether the same can be achieved in vivo. These results have implications for newborn piglet survival and developing an alternative treatment for human obesity.

\section{Acknowledgements}

This work was supported by the Key Foundation for Basic and Application Research in Higher Education of Guangdong, China (\#2017KZDXM009); the Natural Fund Key Projects of Guangdong Province (\#2015A030311006); the Team Project of Guangdong Agricultural Department (\#2017LM2148). All authors made contributions to the conception and design of the experiments. C. W., C. H., and L. H. designed the research. M. X. and J. S. developed the methods and conducted the research. L.C. provided new reagents/analytic tools. G. X. analyzed the data. L. H., C. W., and C. H. wrote the paper.

\section{Disclosure Statement}

The author(s) declare no competing financial interests. 


\section{Cellular Physiology Cell Physiol Biochem 2018;48:556-568 \begin{tabular}{l|l} 
and Biochemistry 10.1159/000491885 & $\begin{array}{l}\text { () 2018 The Author(s). Published by S. Karger AG, Basel } \\
\text { www.karger.com/cpb }\end{array}$
\end{tabular}}

Hou et al.: UCP1/PGC-1 $\alpha$ Induce Pig Preadipocytes Browning

\section{References}

1 Rosen ED, Spiegelman BM: What We Talk About When We Talk About Fat. Cell 2014;156:20-44.

$\longrightarrow 2$ Kissig M, Shapira SN, Seale P: SnapShot: Brown and Beige Adipose Thermogenesis. Cell 2016;166:258U296.

-3 Rosen ED, Spiegelman BM: Adipocytes as regulators of energy balance and glucose homeostasis. Nature 2006;444:847-853.

4 Qiang L, Wang L, Kon N, Zhao W, Lee S, Zhang Y, Rosenbaum M, Zhao Y, Gu W, Farmer SR, Accili D: Brown Remodeling of White Adipose Tissue by SirT1-Dependent Deacetylation of Ppar gamma. Cell 2012;150:620-632.

5 Nedergaard J, Cannon B: The Browning of White Adipose Tissue: Some Burning Issues. Cell Metab 2014;20:396-407.

-6 Cannon B, Nedergaard J: Brown adipose tissue: Function and physiological significance. Physiol Rev 2004;84:277-359.

7 Pfeifer A, Hoffmann LS: Brown, beige, and white: the new color code of fat and its pharmacological implications. Annu Rev Pharmacol Toxicol 2015;55:207-227.

8 Klepac K, Kilic A, Gnad T, Brown LM, Herrmann B, Wilderman A, Balkow A, Gloede A, Simon K, Lidell ME, Betz MJ, Enerback S, Wess J, Freichel M, Blueher M, Koenig G, Kostenis E, Insel PA, Pfeifer A: The G(q) signalling pathway inhibits brown and beige adipose tissue. Nat Commun 2016;7:

-9 Bartelt A, Heeren J: Adipose tissue browning and metabolic health. Nat Rev Endocrinol 2014;10:24-36.

$\checkmark 10$ de Almeida DL, Fabricio GS, Trombini AB, Pavanello A, Tofolo LP, da Silva Ribeiro TA, de Freitas Mathias PC, Palma-Rigo K: Early overfeed-induced obesity leads to brown adipose tissue hypoactivity in rats. Cell Physiol Biochem 2013;32:1621-1630.

11 Nedergaard J, Cannon B: The changed metabolic world with human brown adipose tissue: therapeutic visions. Cell Metab 2010;11:268-272.

12 Virtanen KA: BAT thermogenesis: Linking shivering to exercise. Cell Metab 2014;19:352-354.

13 Wu J, Cohen P, Spiegelman BM: Adaptive thermogenesis in adipocytes: Is beige the new brown? Gene Dev 2013;27:234-250.

14 Kajimura S, Seale P, Spiegelman BM: Transcriptional control of brown fat development. Cell Metab 2010;11:257-262.

15 Shabalina IG, Petrovic N, de Jong JM, Kalinovich AV, Cannon B, Nedergaard J: UCP1 in brite/beige adipose tissue mitochondria is functionally thermogenic. Cell Rep 2013;5:1196-1203.

-16 Shabalina IG, Petrovic N, de Jong JMA, Kalinovich AV, Cannon B, Nedergaard J: UCP1 in Brite/Beige Adipose Tissue Mitochondria Is Functionally Thermogenic. Cell Rep 2013;5:1196-1203.

17 Grimpo K, Volker MN, Heppe EN, Braun S, Heverhagen JT, Heldmaier G: Brown adipose tissue dynamics in wild-type and UCP1-knockout mice: in vivo insights with magnetic resonance. J Lipid Res 2014;55:398-409.

18 Thoonen R, Hindle A, Miranda AB, Yao V, Tainsh R, Buys E, Bloch K, Scherrer-Crosbie M: Brown Adipocyte Dysfunction in UCP1 Knockout Mice leads to Age-Dependent Development of Type 2 Diabetes. FASEB J 2015;29:

19 Enerback S, Jacobsson A, Simpson EM, Guerra C, Yamashita H, Harper M-E, Kozak LP: Mice lacking mitochondrial uncoupling protein are cold-sensitive but not obese. Nature (London) 1997;387:90-94.

20 Lidell ME, Betz MJ, Leinhard OD, Heglind M, Elander L, Slawik M, Mussack T, Nilsson D, Romu T, Nuutila P, Virtanen KA, Beuschlein F, Persson A, Borga M, Enerback S: Evidence for two types of brown adipose tissue in humans. Nat Med 2013;19:631-634.

21 Hou L, Shi J, Cao L, Xu G, Hu C, Wang C: Pig has no uncoupling protein 1. Biochem Biophys Res Commun 2017;487:795-800.

-22 Wu Z, Puigserver P, Andersson U, Zhang C, Adelmant G, Mootha V, Troy A, Cinti S, Lowell B, Scarpulla $\mathrm{RC}$, Spiegelman BM: Mechanisms controlling mitochondrial biogenesis and respiration through the thermogenic coactivator PGC-1. Cell 1999;98:115-124.

23 Villena JA: New insights into PGC-1 coactivators: redefining their role in the regulation of mitochondrial function and beyond. FEBS J 2015;282:647-672.

24 Norheim F, Langleite TM, Hjorth M, Holen T, Kielland A, Stadheim HK, Gulseth HL, Birkeland KI, Jensen J, Drevon CA: The effects of acute and chronic exercise on PGC-1 alpha, irisin and browning of subcutaneous adipose tissue in humans. FEBS J 2014;281:739-749.

25 Lukaszuk B, Kurek K, Miklosz A, Zendzian-Piotrowska M, Chabowski A: The Role of PGC-1alpha in the Development of Insulin Resistance in Skeletal Muscle - Revisited. Cell Physiol Biochem 2015;37:22882296. 


\section{Cellular Physiology Cell Physiol Biochem 2018;48:556-568 \begin{tabular}{l|l|l}
\hline DOI: 10.1159/000491885 2018 & $\begin{array}{l}\text { () 2018 The Author(s). Published by S. Karger AG, Basel } \\
\text { www.karger.com/cpb }\end{array}$
\end{tabular}

-26 Tiraby C, Tavernier G, Lefort C, Larrouy D, Bouillaud F, Ricquier D, Langin D: Acquirement of brown fat cell features by human white adipocytes. J Biol Chem 2003;278:33370-33376.

-27 Shu G, Lu NS, Zhu XT, Xu Y, Du MQ Xie QP, Zhu CJ, Xu Q, Wang SB, Wang LN, Gao P, Xi QY, Zhang YL, Jiang QY: Phloretin promotes adipocyte differentiation in vitro and improves glucose homeostasis in vivo. J Nutr Biochem 2014;25:1296-1308.

28 Zhang Z, Zhang H, Li B, Meng X, Wang J, Zhang Y, Yao S, Ma Q Jin L, Yang J, Wang W, Ning G: Berberine activates thermogenesis in white and brown adipose tissue. Nat Commun 2014;5:5493.

29 Lagouge M, Argmann C, Gerhart-Hines Z, Meziane H, Lerin C, Daussin F, Messadeq N, Milne J, Lambert P, Elliott P, Geny B, Laakso M, Puigserver P, Auwerx J: Resveratrol improves mitochondrial function and protects against metabolic disease by activating SIRT1 and PGC-1alpha. Cell 2006;127:1109-1122.

-30 Argyropoulos G, Harper ME: Uncoupling proteins and thermoregulation. J Appl Physiol 2002;92:21872198.

-31 Lee YH, Jung YS, Choi D: Recent advance in brown adipose physiology and its therapeutic potential. Exp Mol Med 2014;46:e78.

32 Fenzl A, Kiefer FW: Brown adipose tissue and thermogenesis. Horm Mol Biol Clin Investig 2014;19:25-37.

-33 Rial E, Gonzalez-Barroso MM, Fleury C, Bouillaud F: The structure and function of the brown fat uncoupling protein UCP1: Current status. Biofactors 1998;8:209-219.

-34 Puigserver P, Wu Z, Park CW, Graves R, Wright M, Spiegelman BM: A cold-inducible coactivator of nuclear receptors linked to adaptive thermogenesis. Cell 1998;92:829-839.

-35 Ventura-Clapier R, Garnier A, Veksler V: Transcriptional control of mitochondrial biogenesis: the central role of PGC-1 alpha. Cardiovasc Res 2008;79:208-217.

- 36 Wu j, Bostrom P, Sparks LM, Ye L, Choi JH, Giang A-H, Khandekar M, Virtanen KA, Nuutila P, Schaart G, Huang K, Tu H, Lichtenbelt WDvM, Hoeks J, Enerbaeck S, Schrauwen P, Spiegelman BM: Beige Adipocytes Are a Distinct Type of Thermogenic Fat Cell in Mouse and Human. Cell 2012;150:366-376.

-37 Scott JW, Oakhill JS, Ling NX, Langendorf CG, Foitzik RC, Kemp BE, Issinger OG: ATP sensitive bi-quinoline activator of the AMP-activated protein kinase. Biochem Biophys Res Commun 2014;443:435-440.

-38 Eichner LJ, Giguere V: Estrogen related receptors (ERRs): a new dawn in transcriptional control of mitochondrial gene networks. Mitochondrion 2011;11:544-552.

39 Schrepfer E, Scorrano L: Mitofusins, from Mitochondria to Metabolism. Mol Cell 2016;61:683-694.

40 Scarpulla RC, Vega RB, Kelly DP: Transcriptional integration of mitochondrial biogenesis. Trends Endocrin Met 2012;23:459-466.

-41 Zhang W, Schmull S, Du M, Liu J, Lu Z, Zhu H, Xue S, Lian F: Estrogen Receptor alpha and beta in Mouse: Adipose-Derived Stem Cell Proliferation, Migration, and Brown Adipogenesis In vitro. Cell Physiol Biochem 2016;38:2285-2299.

42 Jespersen NZ, Larsen TJ, Peijs L, Daugaard S, Homoe P, Loft A, de Jong J, Mathur N, Cannon B, Nedergaard J, Pedersen BK, Moller K, Scheele C: A Classical Brown Adipose Tissue mRNA Signature Partly Overlaps with Brite in the Supraclavicular Region of Adult Humans. Cell Metab 2013;17:798-805.

43 Veniant MM, Sivits G, Helmering J, Komorowski R, Lee J, Fan W, Moyer C, Lloyd DJ: Pharmacologic Effects of FGF21 Are Independent of the “Browning” of White Adipose Tissue. Cell Metab 2015;21:731-738.

44 Landin Malt A, Cesario JM, Tang Z, Brown S, Jeong J: Identification of a face enhancer reveals direct regulation of LIM homeobox 8 (Lhx8) by wingless-int (WNT)/beta-catenin signaling. J Biol Chem 2014;289:30289-30301.

45 Milet C, Maczkowiak F, Roche DD, Monsoro-Burq AH: Pax3 and Zic1 drive induction and differentiation of multipotent, migratory, and functional neural crest in Xenopus embryos. Proc Natl Acad Sci U S A 2013;110:5528-5533.

46 Sato T, Sasai N, Sasai Y: Neural crest determination by co-activation of Pax3 and Zic1 genes in Xenopus ectoderm. Development 2005;132:2355-2363.

47 Tropepe V, Li S, Dickinson A, Gamse JT, Sive HL: Identification of a BMP inhibitor-responsive promoter module required for expression of the early neural gene zic1. Dev Biol 2006;289:517-529.

-48 Qian S-W, Tang Y, Li X, Liu Y, Zhang Y-Y, Huang H-Y, Xue R-D, Yu H-Y, Guo L, Gao H-D, Liu Y, Sun X, Li Y-M, Jia W-P, Tang Q-Q: BMP4-mediated brown fat-like changes in white adipose tissue alter glucose and energy homeostasis. Proc Natl Acad Sci U S A 2013;110:E798-E807.

-49 Whittle AJ, Carobbio S, Martins L, Slawik M, Hondares E, Jesus Vazquez M, Morgan D, Csikasz RI, Gallego R, Rodriguez-Cuenca S, Dale M, Virtue S, Villarroya F, Cannon B, Rahmouni K, Lopez M, Vidal-Puig A: BMP8B Increases Brown Adipose Tissue Thermogenesis through Both Central and Peripheral Actions. Cell 2012;149:871-885. 